\title{
pH Imaging of Ion Diffusion at Laminar Flow Interface and Estimation of Diffusion Coefficients
}

\author{
Ko-ichiro Miyamoto $^{1}$, Shoko Naito ${ }^{1}$, Carl Frederik Werner ${ }^{1}$, Shigeyasu Uno ${ }^{3}$ and Tatsuo Yoshinobu ${ }^{1,2}$ \\ ${ }^{1}$ Department of Electronic Engineering, Tohoku University, \\ 2 Department of Biomedical Engineering, Tohoku University, \\ 6-6-05 Aza-Aoba, Aramaki, Aoba-ku, Sendai, Japan \\ ${ }^{3}$ Department of Electrical and Electronic Engineering, Ritsumeikan University \\ 1-1-1 Noji-Higashi, Kusatsu, Shiga, 525-8577, Japan \\ k-miya@ecei.tohoku.ac.jp
}

\begin{abstract}
:
A chemical imaging sensor, which is able to visualize the $\mathrm{pH}$ distribution, was combined with a $\mathrm{Y}$ shaped microfluidic channel. $\mathrm{HCl}$ was injected from one inlet and various solutions of chlorides with different cations were injected from the other inlet to form a laminar flow in the channel. The $\mathrm{pH}$ distribution was visualized at the laminar flow interface, where protons and cations were exchanged by diffusion. The apparent diffusion coefficient was calculated by fitting the change of $\mathrm{pH}$ distribution to the diffusion equation, which showed a clear dependence on the size of cations and fell between the diffusion coefficient of protons and that of cations. This result demonstrated the possibility of discriminating ions based on the measurement of their diffusivity by the chemical imaging sensor.
\end{abstract}

Key words: diffusion coefficient, chemical sensor, chemical imaging, laminar flow, microchannel.

\section{Introduction}

The diffusion coefficient of an ion is an essential physical parameter that limits the biochemical and electrochemical reactions in a solution system. However, it is not easy to quantitatively evaluate the diffusion coefficient by experiments. In this study, a method based on a chemical imaging sensor [1,2] was refined and applied to various cations.

Recently, various measurement systems combining a chemical imaging sensor and microfluidics as shown in Fig. 1a have been developed [2-4]. Here, a chemical imaging sensor is a semiconductor-based chemical sensor that can visualize the distribution of $\mathrm{pH}$ values [5-7]. Thanks to its light-addressability, the $\mathrm{pH}$ value can be obtained at an arbitrary position inside the channel fabricated on the sensor surface. In a Y-shaped channel shown in Fig. 1b, the diffusion of ions at the laminar flow interface between two streams can be quantitatively studied [2]. In this study, seven different cations were tested and their diffusivities were compared.

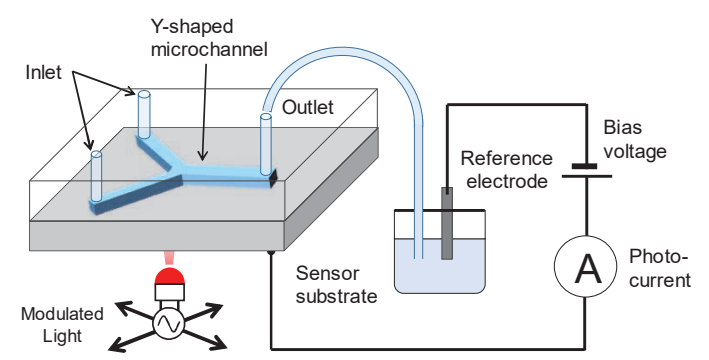

(a)

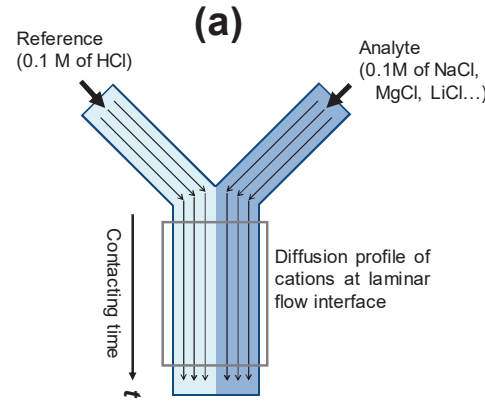

(b)

Fig. 1. Schematics of (a) the measurement system and (b) diffusion at a laminar flow interface in a $Y$ shaped microchannel. 


\section{Experiment}

The measurement system was intrinsically the same as in our previous study except for the structure of the microchannel [2]. In this study, the walls and the top of the microchannel were fabricated with PDMS and ITO-coated glass, respectively, and the ITO layer functioned as a counter electrode. The main channel and two branches were $2 \mathrm{~mm}$ and $1 \mathrm{~mm}$ in width, respectively, and the depth was $160 \mu \mathrm{m}$.

Two streams of solutions separated by a laminar flow interface was formed by injecting $0.1 \mathrm{M} \mathrm{HCl}$ from the left inlet and various solutions of chlorides ( $\mathrm{LiCl}, \mathrm{NaCl}, \mathrm{MgCl}_{2}, \mathrm{KCl}$, $\mathrm{CaCl}, \mathrm{CuCl}_{2}, \mathrm{CsCl}$ ) from the right inlet. In all cases, the concentrations of $\mathrm{Cl}^{-}$were $0.1 \mathrm{M}$ in both streams. Protons and cations diffuse across the interface from left to right and vice versa, respectively. Since the distance along the stream corresponds to the time after meeting of two solutions, the $\mathrm{pH}$ profiles perpendicular to the interface collected as a function of the distance show the dynamics of diffusion.

\section{Result and discussion}

Fig. 2 shows examples of $\mathrm{pH}$ profiles observed in a Y-shaped channel. Broadening of the low $\mathrm{pH}$ region show the diffusion of protons from left to right. The arrows on the left side are $6.5 \mathrm{~mm}$ long, along which $3.7 \mathrm{~s}$ or $15 \mathrm{~s}$ elapses depending on the flow rate.

The apparent diffusion coefficient was calculated by fitting the $\mathrm{pH}$ profiles, which were obtained as a function of time after meeting of two streams, to the diffusion equation. The

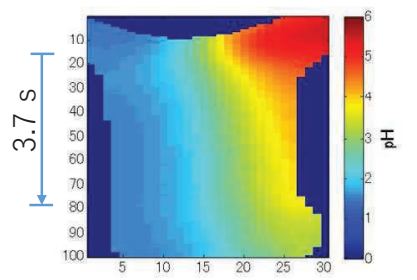

(a)

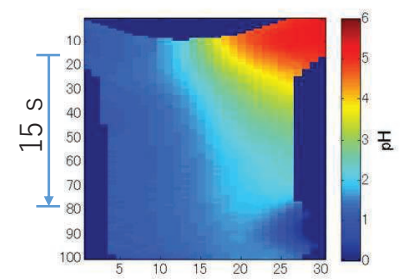

(b)

Fig. $2 \mathrm{pH}$ imaging of diffusion between two streams of $\mathrm{HCl}(0.1 \mathrm{M})$ and $\mathrm{NaCl}(0.1 \mathrm{M})$ at different flow rates of (a) $2 \mathrm{ml} / \mathrm{h}$ and (b) $0.5 \mathrm{ml} / \mathrm{h}$. The actual size of the region measured is $3 \mathrm{~mm}(W) \times 10 \mathrm{~mm}(H)$.

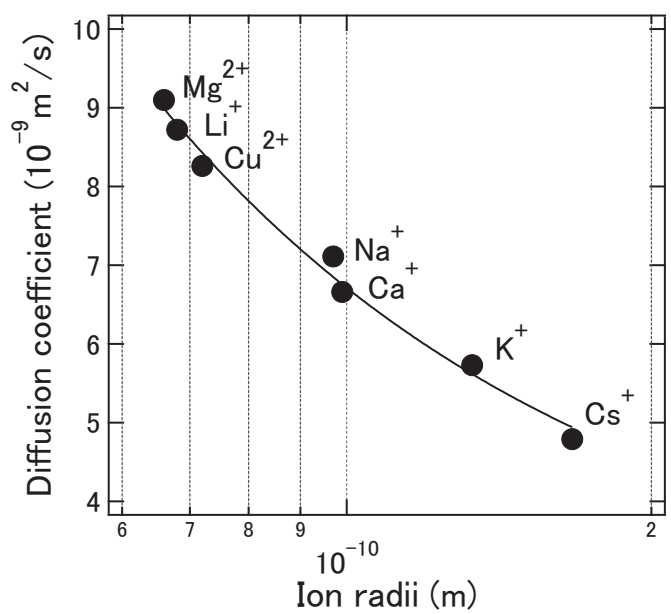

Fig. 3 Diffusion coefficients obtained for various cations plotted versus their ionic radii.

results are shown in Fig. 3, which shows a clear dependence on the size of cations.

It should be noted that these values seem to fall between the diffusion coefficient of protons and that of cations. This is understood as a result of the exchange of protons and cations at the interface, while keeping the overall charge neutrality.

\section{Acknowledgement}

A part of this study was supported by JSPS KAKENHI Grant Number 17H03074. A part of this research was carried out at the Machine Shop Division of Fundamental Technology Center, Research Institute of Electrical Communication, Tohoku University.

\section{References}

[1] T. Yoshinobu, T. Harada, H. Iwasaki, Jpn. J. Appl. Phys. 39, L318-L420 (2000); doi:10.1143/JJAP. 39.L318

[2] K. Miyamoto, H. Ichimura, T. Wagner, M.J. Schöning, T. Yoshinobu, Sensors and Actuators B 189, 240-245 (2013); doi:10.1016/j. snb.2013.04.057

[3] K. Miyamoto, Y. Hirayama, T. Wagner, M.J. Schöning, T. Yoshinobu, Electrochim Acta 113, 768-772 (2013); doi:10.1016/j.electacta. 2013. 08.089

[4] A. Itabashi, N. Kosaka, K. Miyamoto, T. Wagner, M.J. Schöning and T. Yoshinobu, Sensors and Actuators B 182, 315-321 (2013); doi:10.1016/j. snb.2013.03.016

[5] M. Nakao, T. Yoshinobu, H. Iwasaki, Sensors and Actuators B 20, 119-123 (1994); doi:10.1016/ 0925-4005(93)01199-E

[6] M. Nakao, T. Yoshinobu, H. Iwasaki, Japanese Journal of Applied Physics Part 2, Letters 33, L394-397(1994); doi:10.1143/JJAP.33.L394

[7] K. Miyamoto and T. Yoshinobu, Sensors and Materials 28, 1091-1104 (2016); doi:10.18494/ SAM.2016.1364 